\title{
Quality of Life in Patients with Stable Coronary Artery Disease Submitted to Percutaneous, Surgical and Medical Therapies: A Cohort Study
}

Lucas Molinari Veloso da Silveira ( $\square$ lucasmolinari93@gmail.com )

Instituto do Coração: Instituto do Coracao https://orcid.org/0000-0002-3543-594X

Adriana Silveira Almeida

Universidade Federal do Rio Grande do Sul

Felipe C. Fuchs

Universidade Federal do Rio Grande do Sul

Aline Gonçalves Silva

Universidade Federal do Rio Grande do Sul

Marcelo Balbinot Lucca

Universidade Federal do Rio Grande do Sul

\section{Samuel Scopel}

Universidade Federal do Rio Grande do Sul

\section{Sandra C. Fuchs}

Universidade Federal do Rio Grande do Sul

Flávio D. Fuchs

Universidade Federal do Rio Grande do Sul

\section{Research}

Keywords: Cardiac surgery, percutaneous coronary intervention, stable coronary artery disease, quality of life, cohort study

Posted Date: April 6th, 2021

DOl: https://doi.org/10.21203/rs.3.rs-370338/v1

License: (c) (1) This work is licensed under a Creative Commons Attribution 4.0 International License. Read Full License

Version of Record: A version of this preprint was published at Health and Quality of Life Outcomes on November 24th, 2021. See the published version at https://doi.org/10.1186/s12955-021-01886-7. 


\section{Abstract}

Background: Clinical, surgical and percutaneous strategies have been shown similar effectiveness in the prevention of major cardiovascular events in patients with stable coronary artery disease (CAD). The possibility that these strategies have differential effects over health-related quality of life (HRQoL) has been debated, particularly in patients treated outside clinical trials.

Methods: 454 patients diagnosed with coronary artery disease during an elective diagnostic coronary angiography were assigned to Coronary Artery Bypass Grafting (CABG), Percutaneous Coronary Intervention (PCI) or optimal medical treatment (OMT), and followed on average for $6.0 \pm 1.9$ years. HRQoL was assessed by a validated Brazilian version of the 12-Item Short-Form Health Survey (SF-12) questionnaire. The association between therapeutic strategies and scores of QoL were tested by ANOVA and adjusted for confounding in a general linear model.

Results: There was no difference in the Mental Component Summary (MCS) scores in the follow-up evaluation by therapeutic strategies: 51.4, 53.7 and 52.3, respectively, for MT, PCl, and CABG. Physical Component Summary (PCS) scores were higher in the PCI group, when compared to the CABG and MT (46.4 vs. 42.9 and 43.8 , respectively), but these differences were no longer different after adjustment for confounding variables.

Conclusion: In a long-term follow-up of patients with stable CAD, HRQoL was not different in patients treated by medical, percutaneous or surgical treatments.

\section{Background}

Coronary artery disease (CAD) is expected to persist as the major cause of death worldwide at least until 2030. ${ }^{1}$ Clinical, surgical and percutaneous strategies have demonstrated effectiveness to relieve its clinical manifestations and to prevent the recurrence and fatalities, particularly in acute events ${ }^{2}$. The identification of the best therapeutic strategy in patients with stable CAD, however has been controversial.

Randomized controlled trials ${ }^{3-4}$ and their meta-analyse ${ }^{5-6}$ have demonstrated that there is no evidence of superiority of interventional treatments over clinical treatment in the prevention of major cardiovascular events in patients with stable CAD. Recently, the ISCHEMIA and ISCHEMIA-CKD Trials, reported that in patients with stable CAD, and moderate or severe ischemia, an invasive strategy (CABG or $\mathrm{PCl}$ ), compared with a conservative strategy (OMT only) did not reduced the incidence of cardiovascular events or death after a follow-up of approximately 3 years. ${ }^{7-8}$

Most of the clinical trials evaluating strategies for management of chronic CAD, however, have compared patients submitted to $\mathrm{CABG}$ and $\mathrm{PCl}$, but not medical treatment. Overall, these trials demonstrate that there is no significant difference in the incidence of mortality or myocardial infarction in patients treated with either one of the invasive options. However, surgical patients have lower rates of new revascularization procedures during follow-up. ${ }^{9-11}$ 
On the other hand, observational studies comparing CABG with $\mathrm{PCl}$ have suggested that the former can be more effective to prevent major CV (cardiovascular) events ${ }^{12-14}$. In studies that included patients treated clinically, however, the incidence of $\mathrm{CV}$ events has not been substantially different than in patients treated by $\mathrm{CABG}$ or $\mathrm{PCl}$, as we demonstrated in a cohort study recently reported. ${ }^{15}$

Independently of the effectiveness of therapies in the prevention of major CV outcomes, it is important to investigate if patients treated with different strategies have better outcomes in regard to the frequency of symptoms and quality of life. Studies that have addressed this issue, as the COURAGE Trial ${ }^{16}$ and the Ischemia Trial ${ }^{17}$. These trials have demonstrated better health-related quality of life (HRQoL) in patients treated with invasive strategies, when compared to conservative strategies with optimized MT only. In the comparison of the effects of invasive strategies, CABG may have a more durable benefit over HRQoL, than $\mathrm{PCl}^{18}$, as demonstrated in a sub-analysis of the SYNTAX Trial.

Observational studies with all comers could offer insightful information in relation to the effect of different therapies over HRQoL. To our knowledge, there are a few observational studies comparing the effect of different strategies of treatment in participants submitted to OMT, CABG or PCI. ${ }^{19-22}$ These studies had small sample sizes, high rates of losses during follow-up, ${ }^{19-20}$ short follow-up, ${ }^{19,22}$ used different scales for the assessment of HRQoL, and were not adjusted for confounding ${ }^{20-22}$. A metaanalysis identified these and other 30 observational studies assessing the effect of different treatments over HRQoL. ${ }^{23}$ In the total, six studies compared HRQoL in patients treated with PCl or CABG, ${ }^{19-22 ;}$ 24-25 and the remaining reported the effect of individual therapies over HRQoL (after treatment of all participants). This meta-analysis ${ }^{23}$ was not preceded by a systematic review, and compared findings of different study arms without the methods recommended for network meta-analysis, separating arbitrarily for analysis studies with and without outliers. Herein we report the comparison of quality of life in cohort of patients with stable CAD treated cotemporally by clinical, percutaneous or surgical strategies.

\section{Methods}

Details of the study protocol have been described previously. ${ }^{15}$ In summary, patients for this analysis were referred by cardiologists and clinicians for elective diagnostic coronary angiography to a reference tertiary university-affiliated hospital. All comers with a documented diagnose of CAD were included in the study irrespectively of the type of treatment that they were assigned (OMT, PCl our CABG). The option of the therapeutic strategy was taken by the attending physician and, in more complex cases, after a discussion with a cardiovascular surgeon and an interventional cardiologist. Patients with acute coronary syndromes, valvular heart disease, aortic diseases, previous coronary revascularization, class III or IV heart failure, chronic renal disease (previous medical diagnosis or serum creatinine greater than 1.5 $\mathrm{mg} / \mathrm{dL}$ ), history of cancer, or severe psychiatric illness were excluded.

A standardized questionnaire was applied immediately before the coronary angiography. This was considered the baseline interview, and evaluated demographic information, educational history, lifestyle 
characteristics and past medical history.

The follow-up of patients was done through telephone interviews medical records review death certificates and interviews with next-of-keen. A combination of strategies was adopted to minimize losses, which included contact patients by registered letters and interview the attending physicians.

The outcome in this analysis was HRQoL, assessed by a validated Brazilian version of the 12-Item ShortForm Health Survey (SF-12) questionnaire, ${ }^{26}$ which uses 12 questions to assess the influence of eight health domains to score physical and mental health dimensions in the four weeks before the interview. Physical health-related domain investigated General Health (GH), Physical Functioning (PF), Role Physical (RP), and Body Pain (BP), while Mental health-related scales included Vitality (VT), Social Functioning (SF), Role Emotional (RE), and Mental Health (MH). Two scores were calculated: the Physical Component Summary (PCS) and the Mental Component Summary (MCS). ${ }^{27-29}$

All data were evaluated by at least two authors independently, with control of quality on data entry to verify amplitude and consistency. For quality control of the team's performance, $20 \%$ of the protocols were randomly selected to be reviewed by a senior investigator (SCF).

The report of this study was based on the STROBE guidelines (Strengthening the Reporting of Observational Studies in Epidemiology). ${ }^{30}$

\section{Statistical Analysis}

Results are expressed as mean \pm standard deviation (SD) or number (percentage) for continuous and categorical variables, respectively. Continuous and dichotomous variables were analyzed using the Student t-test, one-way ANOVA or chi-square test, as appropriate. When necessary Bonferroni test was applied to identify differences in multiple comparisons. The association between therapeutic strategies and scores of HRQoL were tested by ANOVA and adjusted for confounding using a general linear model. Variables included in the model were those theoretically associated with worse clinical outcomes in patients with coronary heart disease and, therefore, with potential to confound the association of the interventions with scores of HRQoL.Statistical analyses were performed using SPSS, Version 18.0 (SPSS, Inc., Chicago, IL, USA).

\section{Ethical Aspects}

The study protocol was approved by the hospital's Ethics Committee, which is accredited by the Office for Human Research Protections as an Institutional Review Board, registered under no. 13-0171. All participants provided informed consent to participate in the investigation.

\section{Results}

Among 1028 patients referred to elective diagnostic coronary angiography at our institution during the study period, 454 patients had a confirmed diagnosis of coronary artery disease and were treated by 
clinical, surgical, or percutaneous interventions. A total of 402 patients (88.5\%) completed the HRQoL questionnaire in an average follow-up of $6 \pm 1.9$ years and were included in the present analysis. Of these, 112 received $\mathrm{OMT}$ alone, 224 were submitted to $\mathrm{PCl}$ and 66 were submitted to CABG; (Fig. 1). Participants were, on average, aged 60.8 years and most were men $(n=258 ; 64 \%)$.

Table 1 shows that characteristics of the study population, according to treatment groups, were relatively similar. Differences that should be highlighted are the higher prevalence of women in the medical therapy alone group, when compared with $\mathrm{PCl}$ and $\mathrm{CABG}$ ( $46.4 \%$ vs. $31.2 \%$ and $33.3 \%$, respectively). Also, participants who reported a previous myocardial infarction were more often submitted to interventional treatment $(60.6 \%$ and $48.7 \%$ vs. $31.3 \%$, for $\mathrm{CABG}, \mathrm{PCl}$ and $\mathrm{OMT}$ alone, respectively). Patients treated by CABG had higher SXscores in comparison to PCI and OMT alone groups (20.5, 9.3 and 6.6, respectively).

Table 1

Baseline clinical and angiographic characteristics

\begin{tabular}{|lllll|}
\hline Baseline characteristics & MT alone $(\mathbf{n = 1 1 2})$ & PCI $(\mathbf{n}=224)$ & CABG $(\mathbf{n}=66)$ & P value \\
\hline Age (years) & $61.2 \pm 10.0$ & $60.6 \pm 9.1$ & $61.3 \pm 8.1$ & 0.79 \\
\hline Male & $60(53.6 \%)$ & $154(68.8 \%)$ & $44(66.7 \%)$ & 0.02 \\
\hline Race white & $77(68.8 \%)$ & $156(69.6 \%)$ & $54(81.8 \%)$ & 0.13 \\
\hline Years at school (years) & $6.1 \pm 4.0$ & $6.9 \pm 4.3$ & $6.8 \pm 4.1$ & 0.21 \\
\hline BMI (kg/m $\left.{ }^{2}\right)$ & $29.2 \pm 4.8$ & $28.1 \pm 4.3$ & $27.8 \pm 4.2$ & 0.07 \\
\hline SBP $(\mathrm{mmHg})$ & $140.4 \pm 22.5$ & $141.6 \pm 24.1$ & $141.9 \pm 19.8$ & 0.88 \\
\hline DBP (mmHg) & $79.3 \pm 11.7$ & $81.6 \pm 13.1$ & $81.6 \pm 11.6$ & 0.26 \\
\hline Glucose $(\mathrm{mg} / \mathrm{dL})$ & $103.5 \pm 32.4$ & $105.7 \pm 27.2$ & $116.3 \pm 49.3$ & 0.03 \\
\hline HDL-C (mg/dL) & $41.8 \pm 10.6$ & $39.7 \pm 10.1$ & $40.6 \pm 11.4$ & 0.24 \\
\hline Triglycerides (mg/dL) & $140.2 \pm 81.4$ & $148.8 \pm 124.3$ & $156.9 \pm 130.6$ & 0.63 \\
\hline Diabetes melliitus & $36(32.1 \%)$ & $60(26.8 \%)$ & $26(39.4 \%)$ & 0.13 \\
\hline Hypertension & $103(92.0 \%)$ & $213(95.1 \%)$ & $63(95.5 \%)$ & 0.46 \\
\hline Previous myocardial infarction & $35(31.3 \%)$ & $109(48.7 \%)$ & $40(60.6 \%)$ & $<0.001$ \\
\hline HF & $14(12.5 \%)$ & $30(13.4 \%)$ & $14(21.2 \%)$ & 0.22 \\
\hline Creatinine (mg/dL) & $0.68 \pm 0.18$ & $0.69 \pm 0.18$ & $0.72 \pm 0.22$ & 0.44 \\
\hline Current smoking & $13(11.6 \%)$ & $30(13.4 \%)$ & $3(4.5 \%)$ & 0.14 \\
\hline SXscore & $6.6 \pm 8.6$ & $9.3 \pm 6.9$ & $20.5 \pm 9.7$ & $<0.001$ \\
\hline * Variables were described as mean \pm SD or number $(\mathrm{percentage})$ & & \\
\hline
\end{tabular}


The mean unadjusted values of PCS and MCS scores according to treatment strategy are shown in Table 2. There was no difference in MCS between the three groups, with mean MCS for OMT alone, $\mathrm{PCl}$ and CABG of $51.4,53.7$ and 52.3, respectively. PCS scores in patients treated by OMT alone, PCI and CABG were 43.8, 46.4 and 42.9, respectively, (Fig. 2) and the score was significantly higher in the PCI group compared to CABG and OMT alone. The statistically significant differences showed in Table 2 were no longer significant after adjusting for confounding factors (Table 3 )

Table 2

Unadjusted Mean for Quality of Life Scores after CAD treatment in 402 patients undergoing elective coronary angiography

\begin{tabular}{|lll|}
\hline Treatment & PCS * & MCS \\
\hline & Mean \pm SD $(95 \% \mathrm{Cl})$ & Mean \pm SD $(95 \% \mathrm{Cl})$ \\
\hline OMT alone & $43.8 \pm 10.5(41.8-45.8)$ & $51.4 \pm 10.8(49.4-53.4)$ \\
\hline PCl & $46.4 \pm 11.2(45.0-48.0)$ & $53.7 \pm 9.4(52.5-54.9)$ \\
\hline CABG & $42.9 \pm 11.7(40.0-45.8)$ & $52.4 \pm 10.4(49.8-54.9)$ \\
\hline PCS, physical component summary score; MCS, mental component summary; \\
\hline Score of the SF-12 \\
\hline \multirow{2}{*}{ * Between groups ANOVA P value $=0.02$} \\
\hline
\end{tabular}

Table 3

Mean Quality of Life Scores after CAD treatment in 402 patients undergoing elective coronary angiography after adjustment for confounding

\begin{tabular}{|lll|}
\hline Treatment & PCS * & MCS \\
\hline & Mean $(95 \% \mathrm{Cl})$ & Mean $(95 \% \mathrm{Cl})$ \\
\hline OMT alone & $44.3(42.1-46.4)$ & $51.4(49.5-53.3)$ \\
\hline PCI & $46.2(44.8-47.7)$ & $53.8(52.4-55.1)$ \\
\hline CABG & $42.2(39.1-45.2)$ & $52.4(49.8-55.2)$ \\
\hline PCS, physical component summary score; MCS, mental component summary score of the SF-12 \\
\hline $\begin{array}{l}\text { *The differences between groups were not significant after adjustment for age, mean SBP, Syntax } \\
\text { score, years at school and BMI }\end{array}$ \\
\hline
\end{tabular}

\section{Discussion}

In this cohort study of patients with stable CAD treated clinically or by invasive strategies, we identified that all treatment options had similar effect over HRQoL after an average follow-up of $6.0 \pm 1.9$ years. A trend for better QoL in patients treated through PCl was no longer significant after adjustment for the baseline severity of disease and other confounders. 
Health-related quality of life is a multidimensional concept, subjectively perceived, which embraces physical, social, emotional and functional health. ${ }^{31}$ Traditional outcomes of randomized controlled trials and cohort studies may not capture the impact of the intervention on patient's HRQoL. Therefore, assessment of HRQoL has become increasingly important in the management patients with coronary artery disease, which is a chronic disease that classically impairs functional capacity and quality of life ${ }^{32-33}$. Sometimes patients consider the quality of the additional life years gained as important as length of life. ${ }^{34}$

The COURAGE Trial was one of the first studies conducted in patients with stable CAD that evaluated HRQoL changes according to treatment strategies ( $\mathrm{PCl} \times \mathrm{OMT}$ alone). In this trial, the initial improvement in HRQoL in patients treated with $\mathrm{PCl}$ was no longer detected after 12 months. ${ }^{16} \mathrm{~A}$ benefit of invasive strategies compared to OMT on HRQoL was reported in other study. ${ }^{35}$ In another report, patients submitted to revascularization by CABG had a longer improvement in HRQoL than patients treated with $\mathrm{PCl} .{ }^{36}$ The effect of treatments over angina-related health status, assessed by the Seattle Angina Questionnaire (SAQ) and HRQoL, assessed by European Quality of Life-5 Dimensions (EQ-5D) in the Ischemia trial, were a priori sub analysis specified by protocol. Participants treated by CABG or PCl had higher SAQ summary scores than patients treated clinically during a follow-up of 36 months. ${ }^{17} \mathrm{HRQ}$ oL, however, improved similarly along this period of follow-up. ${ }^{17}$ The loss of beneficial effects of invasive approaches over HRQoL at longer follow-up in the Courage and at the Ischemia trials suggest that the short-term effects may be at least in part explained by a placebo effect. Our findings also suggest that any eventual benefit of $\mathrm{PCl}$ and $\mathrm{CABG}$ at short-term follow-up in the real-world care of patients also vanishes in a longer follow-up.

Our findings are hardly comparable to the observational studies that assessed the effect of OMT, PCI or CABG. In addition to the limitations of a few studies that compared the three strategies in contemporary cohorts, ${ }^{19-22}$ they had short follow-up. As far we know, there is only one recent systematic review with meta-analysis addressing this topic, ${ }^{23}$ but non-adherence to the core methods of doing meta-analysis threatens its internal validity.

Our study has limitations that deserve mention. We did not assess the quality of life at the baseline, what could be a bias in the assessment of quality of life in the follow-up. Nonetheless, the underlying reasons for differences in QoL at the baseline were controlled in the multivariate analysis. Limited statistical power due to the sample size may have concealed a beta error. The study was carried out in only one center, which may reduce its external validity. In any case, the characteristics of patients and the diagnostic and therapeutic practices used in our service do not differ substantially from those of other centers. The study of all comers, without the limitations for participation in clinical trials, the comparison of three strategies of treatment, and the long follow-up, can be recognized as strengths of our study.

\section{Conclusion}


In conclusion, we demonstrated that HRQoL of patients with stable CAD is not different after treatment by $\mathrm{CABG}, \mathrm{PCl}$ or $\mathrm{OMT}$ alone after a relatively long period of follow-up. Considering that these strategies have similar effectiveness in the prevention of major CV outcomes, the option for OMT alone seems to be adequate as the first option for the management of patients with stable CAD.

\section{Abbreviations}

CABG: Coronary Artery Bypass Grafting

CAD: Coronary artery disease

CV: cardiovascular

EQ-5D: European Quality of Life-5 Dimensions

HRQoL: Health-related quality of life

MCS: Mental Component Summary

OMT: Optimized Medical Therapy

PCl: Percutaneous Coronary Intervention

PCS: Physical Component Summary

SAQ: Seattle Angina Questionnaire

SD: standard deviation

SF-12: 12-Item Short-Form Health Survey

STROBE: Strengthening the Reporting of Observational Studies in Epidemiology

SXscores: Syntax Scores

\section{Declarations}

\section{Ethics approval:}

The study protocol was approved by the Hospital das Clínicas de Porto Alegre Ethics Committee, registered under no. 13-0171, which is accredited by the Office for Human Research Protections as an Institutional Review Board.

Consent to participate:

All participants provided informed consent. 
Consent for publication:

All the authors have consented for the publication of this version of the article.

Availability of data and material :

All data relevant for this work is available for the community upon reasonable request to the corresponding author.

\section{Conflicts of interest:}

The authors have no conflicts of interest to declare that are relevant to the content of this article.

\section{Funding:}

This study was financed in part by the Programa de Excelência Acadêmica (PROEX), da CAPES (Coordenação de Aperfeiçoamento de Pessoal de Nível Superior) (Auxílio n: 0566/2019); Lucas Molinari Veloso da Silveira had a fellowship from Programa de Bolsa Espescial - Doutorado em Pesquisa Médica No 62/2014

Sandra C. Fuchs had a fellowship from a National Council for Scientific and Technological Development (CNPq), number: 309023/2015-7.

Flavio D. Fuchs has a fellowship from a National Council for Scientific and Technological Development (CNPq), number: 302966/2019-6

Aline Gonçalves da Silva and Samuel Scopel received an undegraduation fellowship from PROBIC FAPERGS-HCPA.

\section{Authors' contributions:}

All authors contributed to the study conception and design. Material preparation, data collection and analysis were performed by Lucas Molinari Veloso da Silveira, Adriana Silveira Almeida, Aline Gonçalves Silva, Marcelo Balbinot Lucca and Samuel Scopel. The first draft of the manuscript was written by Lucas Molinari Veloso da Silveira and all authors commented on previous versions of the manuscript. All authors read and approved the final version of the manuscript.

\section{References}

1. Ayatollahi -. Gholamhosseini H, L. \& Salehi M. Predicting coronary artery disease: a comparison between two data mining algorithms. BMC Public Health 19, 448 (2019)..

2. Bagai -. Dangas A, Stone GD GW, Granger CB. Reperfusion strategies in acute coronary syndromes. Circ Res. 2014 Jun 6;114(12):1918-28. 
3. - Boden WE, ORourke RA, Teo KK, Hartigan PM, Maron DJ, Kostuk WJ, Knudtson M, Dada M, Casperson P, Harris CL, Chaitman BR, Shaw L, Gosselin G, Nawaz S, Title LM, Gau G, Blaustein AS, Booth DC, Bates ER, Spertus JA, Berman DS, Mancini GB, Weintraub WS; COURAGE Trial Research Group. Optimal medical therapy with or without PCI for stable coronary disease. N Engl J Med. 2007 Apr 12;356(15):1503-16.

4. Group -BARI2DS. Frye RL, August P. Brooks MM, Hardison RM. Kelsey SF, MacGregor JM. Orchard TJ, Chaitman BR. Genuth SM, Goldberg SH. Hlatky MA, Jones TL. Molitch ME, Nesto RW, Sako EY, Sobel $B E$. A randomized trial of therapies for type 2 diabetes and coronary artery disease. $N$ Engl $J$ Med. 2009 Jun 11;360(24):2503-15..

5. Katritsis -. loannidis DG JP. Percutaneous coronary intervention versus conservative therapy in nonacute coronary artery disease: a meta-analysis. Circulation. 2005 Jun 7;111(22):2906-12.

6. Stergiopoulos -. Boden K, Hartigan WE P, et al. Percutaneous coronary intervention outcomes in patients with stable obstructive coronary artery disease and myocardial ischemia. A collaborative meta-analysis of contemporary randomized clinical trials. JAMA Intern Med.2014;174(2):232-240. doi:10.1001/jamainternmed.2013.12855.

7. Maron -. Hochman DJ, Reynolds JS, Bangalore HR, O'Brien S, Boden SM, Chaitman WE, Senior BR, López-Sendón R, Alexander J, Lopes KP, Shaw RD, Berger LJ, Newman JS, Sidhu JD, Goodman MS, Ruzyllo SG, Gosselin W, Maggioni G, White AP, Bhargava HD, Min B, Mancini JK, Berman GBJ, Picard DS, Kwong MH, Ali RY, Mark ZA, Spertus DB, Krishnan JA, Elghamaz MN, Moorthy A, Hueb N, Demkow WA, Mavromatis M, Bockeria K, Peteiro O, Miller J, Szwed TD, Doerr H, Keltai R, Selvanayagam M, Steg JB, Held PG, Kohsaka C, Mavromichalis S, Kirby S, Jeffries R, Harrell NO, Rockhold FE Jr, Broderick FW, Ferguson S, Williams TB $J r$, Harrington DO RA, Stone GW, Rosenberg Y; ISCHEMIA Research Group. Initial Invasive or Conservative Strategy for Stable Coronary Disease. N Engl J Med 2020 Apr 9;382(15):1395-407.

8. - Bangalore S, Maron DJ, O'Brien SM, Fleg JL, Kretov El, Briguori C, Kaul U, Reynolds HR, Mazurek T, Sidhu MS, Berger JS, Mathew RO, Bockeria O, Broderick S, Pracon R, Herzog CA, Huang Z, Stone GW, Boden WE, Newman JD, Ali ZA, Mark DB, Spertus JA, Alexander KP, Chaitman BR, Chertow GM, Hochman JS; ISCHEMIA-CKD Research Group. Management of Coronary Disease in Patients with Advanced Kidney Disease. N Engl J Med. 2020 Apr 23;382(17):1608-1618.

9. Hamm -. Reimers CW, Ischinger J, Rupprecht T, Berger HJ, Bleifeld J W. For the German angioplasty bypass surgery investigation. A randomized study of coronary angioplasty compared with bypass surgery in patients with symptomatic multivessel coronary disease. $\mathrm{N}$ Engl $\mathrm{J}$ Med 1994;331(16):1037-43.

10. - The Bypass Angioplasty Revascularization Investigation (BARI) Investigators. Comparison of coronary bypass surgery with angioplasty in patients with multivessel disease. N Engl J Med. 1996;335(4):217-225.

11. Serruys -. Unger PW, Sousa $F J E$, et al. Comparison of coronary-artery bypass surgery and stenting for the treatment of multivessel disease. N Engl J Med 2001;344(15):1117-24. 
12. - Fortuna D, Nicolini F, Guastaroba P, De Palma R, Di Bartolomeo S, Saia F, Pacini $D$, Grilli R; RERIC (Regional Registry of Cardiac Surgery); REAL (Regional Registry of Coronary Angioplasties) Investigators. Coronary artery bypass grafting vs percutaneous coronary intervention in a 'real-world' setting: a comparative effectiveness study based on propensity score-matched cohorts. Eur J Cardiothorac Surg. 2013 Jul;44(1):e16-24.

13. Head -. Milojevic SJ, Daemen M, Ahn J, Boersma JM, Christiansen E, Domanski EH, Farkouh MJ, Flather ME, Fuster M, Hlatky V, Holm MA, Hueb NR, Kamalesh WA, Kim M, Mäkikallio YH, Mohr T, Papageorgiou FW, Park G SJ, Rodriguez AE, Sabik JF 3rd, Stables RH, Stone GW, Serruys PW, Kappetein AP. Mortality after coronary artery bypass grafting versus percutaneous coronary intervention with stenting for coronary artery disease: a pooled analysis of individual patient data. Lancet. 2018 Mar 10;391(10124):939-948.

14. - Panoulas VF, Ilsley CJ, Kalogeras K, Khan H, Monteagudo Vela M, Dalby M, Kabir T, Smith RD, Mason M, Grocott-Mason R, Cummings I, Lüscher TF, Raja SG. Coronary artery bypass confers intermediate-term survival benefit over percutaneous coronary intervention with new-generation stents in real-world patients with multivessel coronary artery disease, including left main disease: a retrospective analysis of 6383 patients. Eur J Cardiothorac Surg. 2019 Nov 1;56(5):911-918.

15. Almeida -. Fuchs AS, Fuchs SC, Silva FC, Lucca AG, Scopel MB, Fuchs S FD. Effectiveness of Clinical, Surgical and Percutaneous Treatment to Prevent Cardiovascular Events in Patients Referred for Elective Coronary Angiography: An Observational Study. Vasc Health Risk Manag 2020;16:285-97.

16. - Boden WE, ORourke RA, Teo KK, Hartigan PM, Maron DJ, Kostuk WJ, Knudtson M, Dada M, Casperson P, Harris CL, Chaitman BR, Shaw L, Gosselin G, Nawaz S, Title LM, Gau G, Blaustein AS, Booth DC, Bates ER, Spertus JA, Berman DS, Mancini GB, Weintraub WS; COURAGE Trial Research Group. Optimal medical therapy with or without PCI for stable coronary disease. N Engl J Med. 2007 Apr 12;356(15):1503-16..

17. Spertus -. Jones JA, Maron PG, DJ, O'Brien, Reynolds SM, Rosenberg HR, Stone Y, Harrell GW, Boden FE Jr, Weintraub WE, Baloch WS, Mavromatis K, Diaz K, Gosselin A, Newman G, Mavromichalis JD, Alexander S, Cohen KP, Bangalore DJ S, Hochman JS, Mark DB; ISCHEMIA Research Group. HealthStatus Outcomes with Invasive or Conservative Care in Coronary Disease. N Engl J Med. 2020 Apr 9;382(15):1408-1419..

18. Abdallah -. Wang MS, Magnuson K, Osnabrugge EA, Kappetein RL, Morice AP, Mohr MC, Serruys FA PW, Cohen DJ; SYNTAX Trial Investigators. Quality of Life After Surgery or DES in Patients With 3Vessel or Left Main Disease. J Am Coll Cardiol. 2017 Apr 25;69(16):2039-2050..

19. - Benzer, W., Höfer, S. \& Oldridge, N.B. Health-Related Quality of Life in Patients with Coronary Artery Disease after Different Treatments for Angina in Routine Clinical Practice. Herz 28, 421-428 (2003).

20. Lukkarinen -. Hentinen $\mathrm{H} M$. Treatments of coronary artery disease improve quality of life in the long term. Nurs Res 2006;55(1):26-33.

21. - Škodová Z, van Dijk JP, Nagyová I. Rosenberger J, Ondušová D. Middel B, Reijneveld SA. Psychosocial predictors of change in quality of life in patients after coronary interventions. Heart 
Lung. 2011;40(4):331-339..

22. - Höfer S. Doering S, Rumpold G. Oldridge N, Benzer W. Determinants of health-related quality of life in patients with coronary artery disease. Eur J Cardiovasc Prev Rehabil. 2006;13(3):398-406.

23. Takousi -. Schmeer MG, Manaras S, Olympios I, Makos CD G, Troop NA. Health-Related Quality of Life after Coronary Revascularization: A systematic review with meta-analysis. Hellenic J Cardiol. 2016 Aug 23:S1109-9666(16)30145-2.

24. Zhang -. Mahoney Z, Stables EM, Booth RH, Nugara J, Spertus F JA, Weintraub WS. Disease-specific health status after stent-assisted percutaneous coronary intervention and coronary artery bypass surgery: one-year results from the Stent or Surgery trial. Circulation. 2003;108(14):1694-1700.

25. - Cohen DJ, Van Hout B, Serruys PW, Mohr FW, Macaya C, den Heijer P, Vrakking MM, Wang K, Mahoney EM, Audi S, Leadley K, Dawkins KD, Kappetein AP; Synergy between PCl with Taxus and Cardiac Surgery Investigators. Quality of life after PCI with drug-eluting stents or coronary-artery bypass surgery. N Engl J Med. 2011;364(11):1016-1026.

26. - Camelier AA. Avaliação da qualidade de vida relacionada à saúde em pacientes com DPOC: estudo de base populacional com o SF-12 na cidade de São Paulo-SP [tese]. São Paulo: Universidade Federal do Estado de São Paulo; 2004.

27. Ware -. Kosinski JE, Keller M SD. A 12-Item Short- Form Health Survey: Construction of scales and preliminary tests of reliability and validity. Med Care 1996; 34(3):220-33.

28. Ware -. Kosinski JE M, Keller SD. SF-12: How to Score the SF-12 Physical and Mental Health Summary Scales. Second Edition. Boston: The Health Institute, New England Medical Center; 1995.

29. Gandek -. Ware B, Aaronson JE, Apolone NK, BjornerJB G, Brazier JE, Bullinger M. Kaasa S, Leplege A. Prieto L, Sullivan M. Cross-Validation of Item Selection and Scoring for the SF-12 Health Survey in Nine Countries: Results from the IQOLA Project. J Clin Epidemiol 1998; 51(11) 1171-1178.

30. - von Elm E, Altman DG, Egger M, Pocock SJ, Gøtzsche PC, Vandenbroucke JP; STROBE Initiative. The Strengthening the Reporting of Observational Studies in Epidemiology (STROBE) statement: guidelines for reporting observational studies. Lancet. 2007 Oct 20;370(9596):1453-7.

31. Coelho -R. Ramos SC, Prata J. Bettencourt P, Ferreira A, M. Cerqueira-Gomes. Heart failure and health related quality of life. Clinical Practice and Epidemiology in Mental Health, vol. 1, article 19, 2005.

32. Lukkarinen - $\mathrm{H}$ and M. Hentinen, "Treatments of coronary artery disease improve quality of life in the long term," Nursing Research, vol. 55, no. 1, pp. 26-33, 2006.

33. Goyal -TM. Idler EL, Krause TJ, and R. J. Contrada, "Quality of life following cardiac surgery: impact of the severity and course of depressive symptoms," Psychosomatic Medicine, vol. 67, no. 5, pp. 759-765, 2005.

34. Thompson -. Yu DR CM. Quality of life in patients with coronary heart disease. I: assessment tools. Health Qual Life Outcomes 2003;1:42.

35. - TIME Investigators. Trial of invasive versus medical therapy in elderly patients with chronic symptomatic coronary-artery disease (TIME): a randomised trial. Lancet. 2001 Sep 22;358(9286):951-7.. 
36. - Cohen DJ, Van Hout B, Serruys PW, Mohr FW, Macaya C, den Heijer P, Vrakking MM, Wang K, Mahoney EM, Audi S, Leadley K, Dawkins KD, Kappetein AP; Synergy between PCl with Taxus and Cardiac Surgery Investigators. Quality of life after PCI with drug-eluting stents or coronary-artery bypass surgery. N Engl J Med. 2011 Mar 17;364(11):1016-26..

\section{Figures}

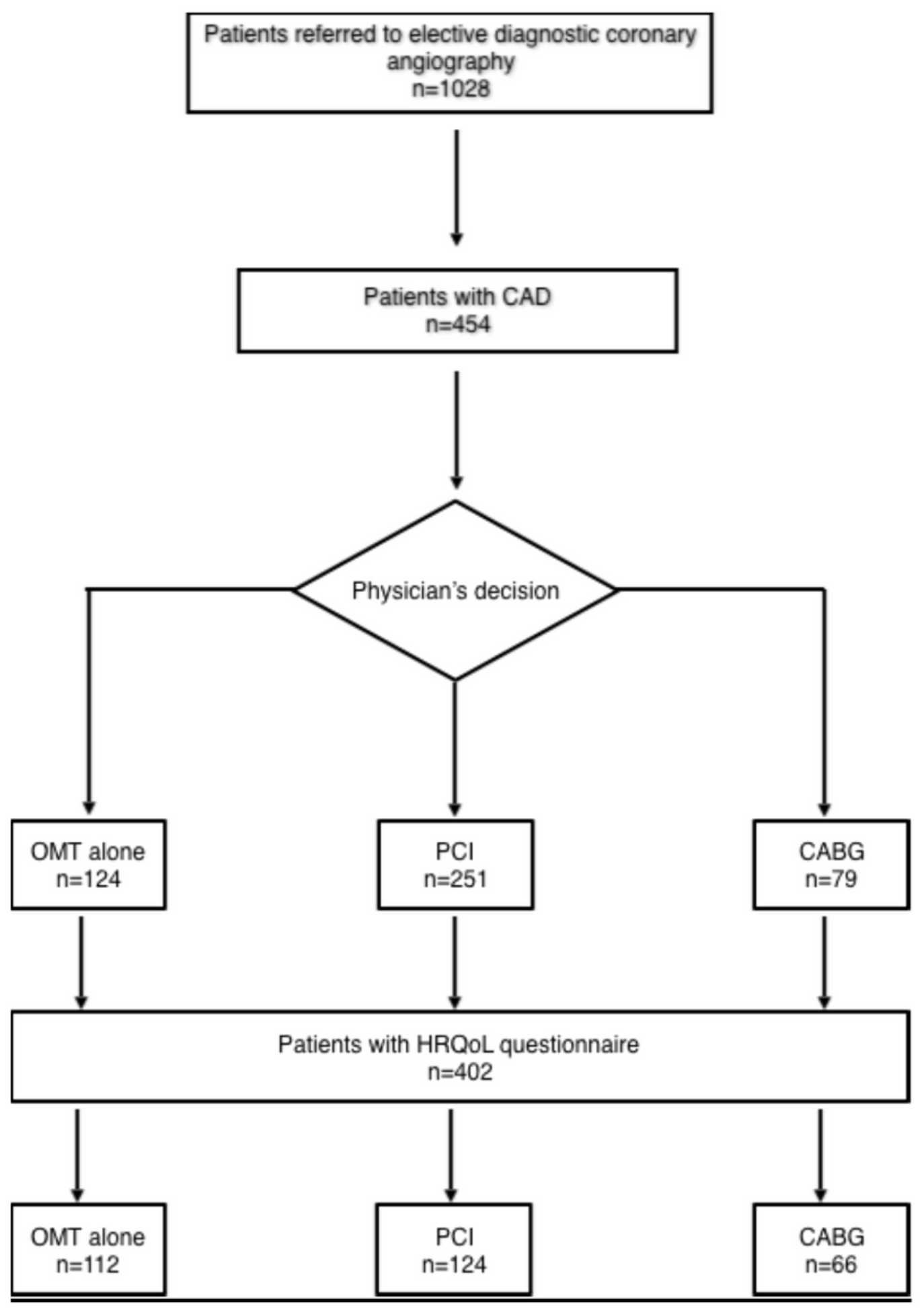


Figure 1

Study Flowchart

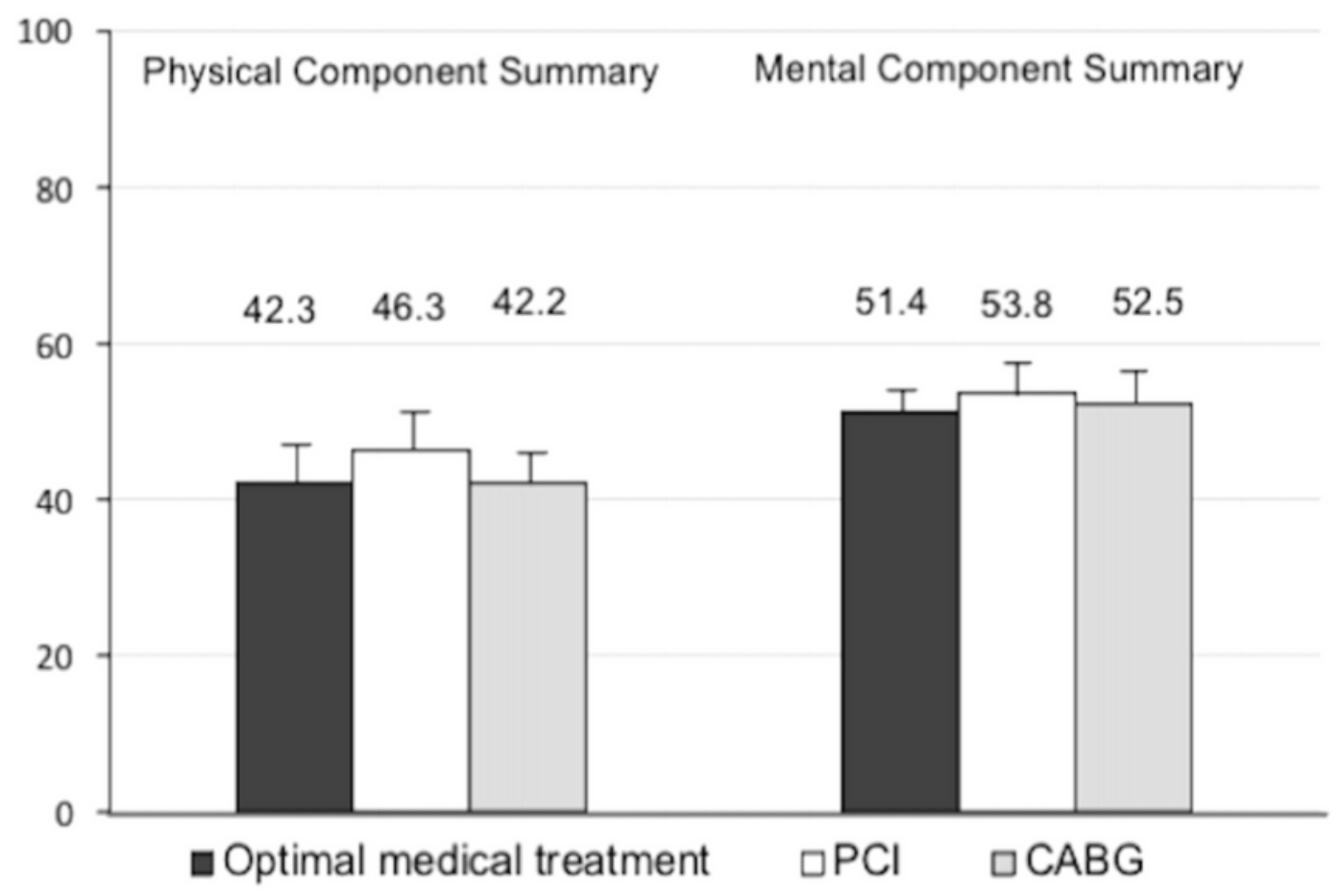

Figure 2

Mean Quality of Life Scores after CAD treatment in 402 patients undergoing elective coronary angiography after adjustment for confounding 